\title{
The Political Subject in Globalization: the Discussion Agency
}

\begin{abstract}
From the defining trends of a globalized world, I expose an analysis of the systemic effects they produce in different spheres of social life, such as the guidelines that structure, in a systemic sense, the insertion of social agents, as well as the way they influence their traditional forms of intervention and participation in the course of social processes and decision-making. The trends of increasing complexity and indeterminacy inherent to globalization produce changes in the economic dynamics of the world market and effects that disrupt the institutional, legal-political frameworks of states. So, when analyzing such transformations, I take on the radicalization of the questions about the possibilities of inclusion or exclusion of the social agents, and the density of the fragmentary effects on the formation of collective identities (and, therewith, of the debate on the opportunities or restrictions of political intervention, organization and mobilization-in other words, the range of probability of their constitution as political subjects). These social and structural transformations update the basis of the theoretical, philosophical and sociological debate on the quality of the agency of social subjects, for which I consider the task of asking whether the dynamics of globalization block the possibilities of intervention of some relevance or, on the contrary, there is scope for resistance and even ways of influencing constructively.
\end{abstract}

\section{An approach to globalization}

Sociological research set out to characterize the organizational structures of modern-contemporary social systems tends to privilege the logic of a growing differentiation that -beyond the segmentary historical forms, or through forms of stratification-has the modality of functional differentiation, in which each subsystem (economic, political, juridical, cultural, scientific, etc.) operates according to specific languages, techniques and values, which are not commensurable, and allows for their autonomous specialty (Luhmann / De Giorggi 1993, pp. 279-339). In line with subsystems differentiation, processes of interdependence occur through functional couplings that integrate the social system, which

Griselda Gutiérrez Castañeda, Universidad Nacional Autónoma de México (UNAM)

Ә OpenAccess. ( 2018 Griselda Gutiérrez Castañeda, published by De Gruyter. (cc) BY-NC-ND This work is licensed under the Creative Commons Attribution-NonCommercial-NoDerivatives 4.0 License. https://doi.org/10.1515/9783110492415-002 
reveal a flexible and diffuse dynamic, which in turn leads to the break in the concert of the specific weight of each functional domain with causal, hierarchic or centered standards, giving rise instead to a polycentric tendency.

Following this logic, the increasing processes of complexity and indeterminacy in post-industrial societies are explained, and their effects may be noticed at the level of understanding, disposition, adaptation, organization and practical control by social agents. Danilo Zolo's interpretation in this respect (with which I agree) notes that the plurality of spaces and practices in their differentiation and semantic specialization, while diversifying and increasing the flexibility of social behavior, introduces an increase in the number of intervening variables that deplete the established intellectual resources operability and makes understanding more precarious. Likewise, increasing interdependencies, and the contingent and diffuse nature of interaction between these spaces, obstructs forms of social intervention when predictions are unlikely, since the known intelligibility and control schemes (e.g. causal, linear schemes, etc., or criteria such as centralization, domination/subordination)-effective until very recently as hierarchical structures and defined attributions-lose validity; there is an unfolding of the referents of certainty. Indeed, it is possible to predict why they are considered regularities, tendencies according to causal schemes; or of a similar nature, if this possibility is diluted, then, in a reflexive sense, we speak of indeterminacy.

In light of the so-called 'spheres of social action' (Weber) that were regulated by basic criteria and norms or accepted and routine techniques, according to which defined roles and possible schemes of action were stipulated, in the now characterized 'functional domains', these are replaced by contingent and flexible criteria. With the displacement of shared and institutionalized beliefs, or of positive or negative motivation schemes to encourage or discourage behaviors, their place is occupied by polyvalent value scales that generate difficulties of accommodation and location within these spaces. In turn, the ranges of social mobility are enhanced as a result of the differentiation of experiences that, by blocking routines or opening new options, can generate insecurity, along with destabilizing effects.

The repercussion of these tendencies is that diverse experiences tend to be shaped by the dynamics of functional domains rather than being an expression of the purposes of social agents, for whom the roles they must play are increasingly unstable, and for whom the diversity of functional needs and expectations to be met, the possible options of profusion of services, the lack or abundance of information to be processed, and the urgency to respond are all greater, which generates uncertain choices regarding opportunities or risks, as opposed to "a kind of 'selective overload"' (Zolo 1994, pp. 19-21). 
In order to abound in some of these systemic effects on the perception and practices of the social agents, I will approach those macro trends that account for the functioning of the social system in a globalized world, which are relevant for our analysis. Based on the internationalization of exchanges between countries and regions that has been characteristic of market societies, what today prevails in the intensification and complexity of cross-border and transnational interconnections, is a displacement of the space referent, starting from a reconfiguration of the temporal referent (Held 1996, pp. 380-381), which takes on centrality by the impulse of what is justifiably called 'revolution in communication'. Techno-scientific developments in communication-which reach the level of IT, robotics and 'mass media'-boost the production and processing of information, the speed and expansion of its distribution and the plasticity in its forms and in the different levels of use, in such a way that when applied to the execution of projects and commercial, scientific and technological exchanges, they practically erase frontiers and permeate all levels of activity: economic, political, technological, military, legal, cultural and environmental areas.

Among the systemic tendencies that globalization entails (such as complexity, indeterminacy, interdependence, mobility), I am interested in highlighting the flexibility of connections and the widespread effect of deregulation. The extensive use of new technologies that impels (by intensifying the financial transactions according to trade flows, the investment and the migration) a great dynamism and complexity to the markets, requires-while it feeds backconditions of flexibility. As a defining criterion of the current capitalist regime, it displaces traditional forms of production and privileges tertiarization, and with this, the organization of enterprises is decentralized and merchandized. This, in the face of greater competition and uncertainty, diversifies organizational and transactional modalities, so that this criterion has an impact on the regulations established for the sake of greater openness and release of restrictions.

Such transformations have a substantial impact on the labor market (as precarious salary conditions prevail), as well as on stability in work, and the conditions under which it develops; tertiarization powers sectors such as services and maquilas, increases forms of outsourcing and a tendency to "deslaborizar las relaciones de trabajo" (Yáñez 2004, pp. 85 and 103)-which translates to say that it dilutes or blurs the labor nature of work relations, as informality increases both in the relationship and in the labor spaces.

Flexibility, beyond the extension of the range of investment and profit opportunities, and when coming into tension with the established legal routines, standards and procedures, exerts pressure for a relaxation or open fracture of the same, which in turn leads to the establishment of highly permissive legal reforms (of investment, commercialization and labor) or the imposition of practi- 
ces of open illegality. Certainly, common regulatory and procedural forms operate with temporalities that short-circuit the potential and speed of new technologies-but the latter, together with the current modalities of organization and competition as resources of neoliberal economic policies, produce an effect that (oxymoronically) 'institutionalizes' deregulation, prioritizing the logic of the market and reducing the policies of intervention and regulation on behalf of the State.

The combination of global trends and neoliberal adjustment policies, by prioritizing the extraction of benefits for global corporations, accentuates inequality in the development of entire countries and regions, as well as high costs in human development, reflected in the increase of unemployment rates, the rising costs of services and an exponential growth of migratory flows.

\section{Mechanisms of inclusion and exclusion in a globalized world}

The confluence of the aforementioned factors and their consequences explains why practical and theoretical debates about the effect on the conditions of social agents' insertion in these scenarios revolve around the notions of 'expulsion' and 'social exclusion' (Sassen 2015; Saraví 2009). In my opinion, the interpretations given to each of them are not in contradiction. With regards to 'expulsion', the problem is analyzed from the logic underlying the organization of functional domains, which is why a homeostatic dynamics that operates in terms of preserving the social system's own equilibria tends to prevail, which filters and expels the disrupting factors (Zolo 1994). It is a dynamic that would allow us to understand that in the practices of advanced capitalism's accumulation, its axis is the procurement of stability, investment and extraction of benefits-even when the expulsion by way of 'collateral effects' implies intensification of unemployment rates, of extreme poverty and the naturalization of the absence of any link with educational training and the labor market of broad social sectors; as well as the displacement of populations derived from the predation of their lands by the extractive industry, and a trend of mass migration (particularly that which results in statelessness) and openly illegal practices, such as people trafficking.

Likewise, the theory of 'social exclusion' seeks to interpret the diversity of these extreme cases of deprivation and marginality of some groups, along with the broad social sectors whose situation is one of 'unfavorable integration', as a result of the accumulation of disadvantages, since they seek forms of integration in the labor market despite the deficiencies and obstacles. Its theoretical 
performance is of interest because, apart from recording extreme cases of exclusion, it tries to understand the new forms of social configuration based on contemporary forms of inequality, differentiation and polarization (Saraví 2009, p. 24), and allows us to problematize the new forms of integration and social agents.

I consider that these interpretations are key to appreciating the effects of the transformations referred to above. In that sense, it is important to point out that among the criteria that gave support to the integration of the modern western political-social ordinances was inclusion, in terms of freedoms and protection, and codified in the formal character of juridical-political membership. Nevertheless, inclusion was always materialized in terms of opportunities that may be of different types, but, relevantly, in economic opportunities. And it is precisely this that is now diluted or made precarious by prevailing conditions of labor instability, forms of outsourcing, low wages, and as a whole, lack of protection and job insecurity of people as workers. This implies that as a result of the uncertain and reduced opportunities and poor quality, agents fragmentarily face, derived from disappointment and restructuring of expectations, their attempts to insert and adapt to new scenarios. This is intensified by recording those sectors that operate from the informality or open illegality to those who access social fringes in a marginal condition, including the masses of undocumented migrants in a significant proportion.

The subsumption of the political subsystem to the logic of the economy is, among other reasons, what underlies many of the transformations of its attributions and competences; it explains the weak presence, and even the absence of the State in the mediation and interlocution tasks able to set limits to the abuses of the business sector, as well as in its nature as a demand referent.

Historically, the compliance of government tasks by nation-states required the construction of a system of attributions and competences according to legal, authority and control capacity regulations. This implied, in a functional sense, operating in a centralized and binding manner within defined territorial frameworks, the faculty for the distribution of resources, along with the creation and regulation of conditions and opportunities for economic, political and social exchanges aimed at political integration and, of course, conflict managementas well as the sovereign attribution with respect to deciding between peace and war, and determining who should be members of that community and who should not. The link between the State and members of the political order according to the status of citizenship was to determine the levels of responsibility to provide welfare, protection and scope of rights, and the type and enforceability of obligations, their compliance outlining criteria of membership, creating an institutional framework capable of functionally generating stability and continu- 
ity, and in a relevant way a civil connection that socially and symbolically would have guided forms of socialization, belonging and the integration of individuals according to roles.

Today, growing interdependencies tend to dilute territorial boundaries and centralized operation, given the proliferation of power and decision-making centers-such as hegemonic states or regions, transnational institutions, and legal and illegal profitable corporations-according to the influence of functional connections that exert global market sectors such as financial, technological and service sectors. This, as a whole, produces an inflation of the states' capacity for resolution and a tendency to outsource their authority and decision-making-in other words, their loss of sovereignty.

As Jacobson points out in his analysis of how the State is taking on new forms by losing primary qualities of its institutional tasks: “... the state remains critical as the mediating mechanism, the node, of a variety of international institutions and global processes" (Jacobson 1997, p. x, my italics). This 'node' is one in which corporate interests and transnational political agreements are crossed, and whose mediation takes place under conditions of flexibility and deregulation, which impairs its institutional functioning in and on its borders, such as the loss of control of its borders in relation to migratory flows.

When the State submits to the pressures of agents and global dynamics and gives rise to the systematic disengagement towards its governed ones (since, far from dosing the effects of these tendencies, it contributes to the intensification and cancellation of opportunities), an overload that people face under conditions of lack of protection and uncertainty takes place. The effects of this overload are diverse, not only at the level of generating strategies of survival, but also in the fracture of the citizen-State pact, as the instances of interlocution dilute. Typically, productive work as a structuring of existence has led to the political codification of mobilization, organization and communication initiatives aimed at demanding inclusion and redistribution (Garretón 1997). Instead, there is a growing dispersion of organizational initiatives and the disarticulation of traditional collective actors-in fact, not only a significant reduction in forms of union organization, but also a weakening of the labor movement and a culture of the working class is registered, that at the time could provide some protection against the corporate interests (Castles / Miller 2003, p. 36).

A political reading of the fracture of the pact leads us in two directions. The first is one in which, by operating according to a self-referential dynamics, the party system and the state institution, through prioritizing its self-preservation and restricting its functions to the mere conservation of stability and the complexity of the social system, causes its programs and decisions to be foreign to the social requirements of its governed ones, which in turn accentuates the def- 
icits of its representation function. The effect is twofold: from the level of the governed, it is the loss of the civic bond, given the experience that the channels of political communication are inoperative and exhausted-that they are affected and mere observers of the course of political decisions; and from the political subsystem level, the effect is a 'deinstitutionalization' (Santiago 2015; Zolo 1994)-i.e., the loss of its political capacity to structure forms of identity and integration of political community.

In the other direction, when the states operate under the pressure of the global economy and the systemic effect of expulsion (in which migratory flows increase), the tendencies of flexibility and deregulation that manifest in a loss of control of the borders lead to the application of ambiguous strategies (in which the economic benefits of these presences are extracted, but the political integration of the immigrants is reluctant; in practice, forms of insertion are given due to the need to offer some services, which can be interpreted as rights for those who do not have membership) that fuel a competitive struggle for access to services between citizens and resident migrants. They also lead to a devaluation of citizenship for the local ones when facing the displacement of the bond between membership and rights, as well as for immigrants whose access to services does not go hand in hand with loyalty to the political institution. In addition to the resignification of the civic link in the form of a utilitarian link, if the State proceeds in this way, in relation to border control as well as to the meaning of migratory policies, it is interpreted by citizens as incapacity in the exercise of its sovereign power, which puts in question its authority and legitimacy (Jacobson 1997, p. 6).

We know that the figure of the pact has been, both symbolically and practically, the guideline for institutionalizing forms of political communication, and that fictio juris has had a theoretical and practical performance, which allows us to conceive of the construction of an order as a product of concerted sovereign wills, and which in turn is concomitant with the conception of the active role of its members and the practical forms of organization and participation. For this reason, it is no minor fact, but rather of the greatest transcendence, that the political frameworks of containment tend to weaken and the political referents of interlocution are erased-because it leads to the fact that the policy of the nation-State loses relevance, as well as to the prevailing of a disaffection with politics. 


\section{The role of the agency under debate}

The consequences that these processes generate are very complex, due to the type of problems, the diversity of reactions and the proliferation of social and political presences marked by fragmentation and disarticulation-multiple presences such as:

- actors that in a more conventional way maintain politics as the axis, more as an expression of survival than for a management or articulation capacity;

- social movements that are by right territorial or ethnic, with different degrees of articulation;

- large sectors involved in generating strategies of survival, whether politically passive or whose conjunctural appearance is disorganized and defensive;

- others that are far from the traditional forms of political integration, and that tend to be guided by symbolic and expressive ways in order to explore and affirm identity in a self-referential way, or to generate solidarity relations and groups by affiliation with subjects of the vital or daily sphere, as well as by ascriptive identity (age, sexual, religious, etc.);

- civil groups such as NGOs and CSOs, with varying degrees of organizational capacity and expertise, according to thematic agendas such as human rights, gender, environmentalism and pacifism (among others), exploring ways of recomposing and reframing intervention and political communication that are not constrained to the interlocution with the political system;

- groups as transnational actors such as anti-globalization movements; and

- extra-institutional presences such as factual powers.

There is no doubt that complexity, increased differentiation and greater mobility contribute to this proliferation of presences. At first glance, this can be read as a symptom of plurality and an expression of new alternatives, but a more in-depth approach is needed, since they are phenomena that go hand in hand with important transformations and the radicality of certain problems that make politics and the State appear as insufficient or impotent to face them, to the point where there is an increase of behaviors of detachment from the traditional forms of socialization and integration that contribute to the dilution of the public sphere.

In terms of the political system, the problem may be a question of governability-but in terms of the governed ones, the problematic acquires greater density because the weakening of binding decisions, the non-adherence to institutional channels, and the transformation/dilution of political communication all have repercussions on the quality of the protective and binding functions 
that are the responsibility of institutions, and whose consequences affect the various spheres of social life. Moreover, in a practical sense, justified doubts arise about the relevance of any initiative of participation, since the current tendencies seem to impose a dynamic in which the action, the initiative, the intentionality or the pretensions of control (both practical and political) tend to lack effectiveness or even sense, by neither influencing the agendas (thus translated into political decisions) nor affecting the dynamics of the system.

These doubts, in a reflexive and political sense, reposition: firstly, the theoretical conceptual debates on the role of political agency, on its relation to the structure or social system, on the validity of subjectivist-mentalist traditions of action in its instrumentalist and/or normative modality, or on the functionalist tradition and the weight of the constraint of the structure; secondly (within societies of great complexity and indeterminacy), the unavoidable questions about the nature of the individual and collective agency, as a symptom of what the explanation of its occurrence may be; and finally, to decipher the tenor of new collective actors, as well as the potential of their mobilizations.

In order to continue developing the last two problems, in a non-exhaustive approach, I will address the first one, by contrasting them with some of the theses of Giddens's structuration theory (in which the author tries to reconcile the dimension of the action and the system), and with the systems theory in the version of Luhmann and Zolo, of whose theses I have developed some throughout these pages. But first I must refer to a condensed image of the contemporary reality of which, with their variants, both theories give us an account, and that in Melucci's words could be called “"planetarization' of the system”, by which he indicates that the system has already found its limits, and that the intervention of the agents is restricted thereto. Melucci conceives of a planetarization in which there is no longer space (because the system was transformed into a single space), nor is there:

... time beyond the system. We know that the great project of industrial capitalism was oriented towards the future, a project for a society that would come, that of the wealth of nations, of the progress or the kingdom of freedom. We now know-and the dramatic reminders of the possible catastrophe contribute to this-that there is no time beyond the internal time of the system, that there is no longer any society that awaits us beyond that which we are capable or not of building; better still, in which we are already immersed; only one that we can make exist from now, within the tensions of the systemic balance. (Melucci 1996, p. 294)

Indeed, contemporary analyses have transcended the disjunctive as to whether the heuristic key is the 'action' or the 'agency' to account for the processes of socialization of the individual and processes of social change-a disjunctive encod- 
ed between subjectivist and objectivist traditions, such as that of a strong individualism and a powerful conception of action, for which the dimension of the context seems to be subsidiary; or those in which the emphasis is placed on the structure or the system that frames the subjects according to positions and roles, displacing the autonomous and rational 'action' according to ends, by the 'agency' of subjects as carriers (Träger) of structures.

Giddens's theoretical intervention is an example of this. In his structuration theory, the constitution of agents and that of structures are not independent phenomena and "do not form a dualism but represent a duality" (Giddens 1995, p. 61). He seeks to explain that the structure integrates rules (guidelines and codes of meaning) and resources (of authority and allocation and control) that intervene recursively in the reproduction of social systems, which are not alien to human action and its reflexive record, although this may be limited; the crucial argument is that "Structure should not be assimilated to constraint but is both constrictive and enabling" (Giddens 1995, p. 61).

The core of this argument, in which Marxian echoes are present, is that if action is associated with intentionality, it is an incontrovertible fact that social processes are not an intentional product. This does not prevent them from being the work of practical intervention of men within objective conditions; without ruling out the action in the practical and reflexive sphere of the individual, Giddens makes a theoretical shift towards the term 'agency', understood as the capacity to do things, as a matter of power, to produce effects, to abstain or to act otherwise-an interpretation with which he would bet on maintaining the active role of social agents. In the spirit of dismissing pretensions of structural causation that determine social action, while at the same time recording that the resources of the structure generate forms of social reproduction (and thus stabilize relations in an institutionalized form that give rise to a systemic reproduction, as well as to the production and reproduction of a social action), Giddens is interested in highlighting that such properties and structural resources are eventually used and reproduced by agents in the course of their interactions, which may result in "processes of selective 'filtering information', whereby strategically located actors seek to reflexively regulate the general conditions of a systemic reproduction, either to maintain things as they are or to change them" (Giddens 1995, p. 64).

In order to reinforce this proposal, he applies the strategy of refuting some approaches of the functionalist tradition, in which he encompasses very diverse perspectives (structuralist, poststructuralist, evolutionist, systemic) with regard to the emphasis he attributes to them in terms of the constraints produced by social structure and which, in his opinion, make subjects appear as non-reflexive constraints, as an undisputed causal force that restricts or cancels options, be- 
fore which action is diluted and at the very least gives rise to mere reactions-a strategy that, despite the expanded nature of its analysis, is not without simplifying dyes.

I consider that this position does not necessarily strengthen his interpretative proposal. Certainly, neither do those who support the thesis of the decentralization of the subject (Althusser) omit the reflexive contest of the agents (which does not exempt them from subjection), nor do the adaptive forms by which the agents respond to systemic and structural tendencies that overload them, cancel the reasons and the motifs that agents give themselves to process their 'options', with which the role of structural tendencies are in no case equated with natural forces. For Giddens, the form of arguing against those formulations that conceive that systemic reproduction dilutes the place of action (by holding that functional needs only produce functional consequences), is to hold that "[s]tructural constraints do not operate independently of agents' motifs and reasons to act” (Giddens 1995, p. 211)-an argument that he considers strong enough to restore a place for the agency to be conceived of as a power, such as the capacity and the possibility of producing a disruptive, or a novelty effect.

In general terms, I consider that the systemic perspective would be far from maintaining a dualism between system and agents in their interpretations of the system integration process. This would agree with Giddens that in this globalized world, there is a kind of "rupture between systemic integration and social integration” (Giddens 1995, p. 213), and wouldn't contest the fact that human action has contributed to the generation of this scenario. These points of convergence present no obstacle for this theory to support the line of argument that it is precisely tendencies of increasing complexity and indetermination (as well as uncalculated evolutionary pressures) that make complex societies operate according to a systemic logic of homeostasis, with the effect that the action appears as something irrelevant to a self-produced reality (Zolo 1994, p. 148-149). Such an interpretation, far from omitting the consideration of how social agents are reflexively and emotionally involved, and with pretensions to influence, instead reframes the questions: what kind of 'action' is at stake; what kind of symptom (or a symptom of what) are these interventions; and, of course, what is the potential of the agency?

At this point it is important to dwell on the mechanism of 'adaptation' and the use of the term by Luhmann and Zolo, in contrast to Giddens's questioning of the application of some of the theories of social change (particularly his debates with Parsons, to whom he attributes an update of the evolutionary theory), criticisms of which revolve around the empty, illusory and narrow use of the concept, which makes it limited to account for changes in the social plane. 
Of course there may be cases in which its use lacks precision and explanatory value-but it is certainly its commitment to the potential of agency that gives rise to the categorical tone of his criticisms. It is only plausible if one aspect, or both, of its meaning is extended: if other societies (i.e., the 'social environment') are included in the term 'environment' and/or if any important social process that seems to increase the chances of maintaining a society in a form that can be considered stable is virtually considered as 'adaptation'. But once that step has been taken, the concept becomes so vague that it is useless as a means to explain anything (Giddens 1995, p. 262).

From the systemic perspective, although it is emphasized that the functionality of the social system as a self-produced reality operates outside our rational and technical control and our ethical-moral idealizations, this does not mean that the system can dispense with its 'environment', which can be internalized as system information. The implications of this operation are double: on the one hand, that it contributes to the stabilization or equilibrium of the system; and on the other hand, that agents, as part of the environment, generate patterns of assimilation and accommodation in the form of learning. So, if one considers the self-referential tendency of the political system and the distortion of the criteria attributed to 'political action', such as its reflexive, critical and powerful nature, it is necessary to think about which mechanisms of insertion come into play -especially if we take into account the fact that social agents systematically deal with adverse conditions for the possibility of rational choices, to make meaningful interactions at the level of political communication, and to achieve some relevant influence on the control of procedures, as well as generalized possibilities of forming an informed opinion or developing a reflexive judgment, allowing them to evaluate the problems and options presented.

This is where the explanatory performance of the adaptation mechanism is noticeable, leading to the transformation of frustration into learning, and of disappointments into adaptive behaviors, which (although they reserve a certain place for human agency, as Zolo emphasizes) does not mean that the integration of the agents is not in accordance with functional tendencies that preselect possibilities, limit alternatives and over determine social expectation (in terms of 'opportunities')-and with that, the nature of 'decisions' is shaped.

Examples abound that may seem extreme, but are far from extraordinary in these times, when precariousness and deregulation lead to the expulsion of migrant masses, and the devaluation of this type of work and the advantages that can be extracted attract them to certain countries or regions. There is no doubt that objective factors and systemic tendencies are put at risk to explain these massive flows, nor is there any doubt with respect to the contest of subjective factors such as the expectation of the 'opportunities' represented by the destina- 
tion, or by fulfilling the purpose of family unification, including cultural and religious motivations. Therefore, it cannot be argued that agency has a role in this framework (Castles / Miller 2003, p. 9)-but it is not outside the discussion to resolve what kind of 'decision' it is.

When the conditions of vulnerability and precariousness in the countries of destination lead immigrant groups to form alternative networks of solidarity, the debate arises as to whether these initiatives are an expression of 'emerging political subjects' (Sassen 2003, p.26). This discussion is, of course, inescapable; it cannot be ignored that in an adverse context these networks are aimed at solving material and psycho-social needs, such as preserving identity and forms of belonging, through which in such networks the nature of survival strategies prevails.

Confronted with expressions of this nature, many questions arise. If we start from the fact that politics is a type of strategic action aimed at remedying something more than immediate needs (i.e., that it is guided by more far-reaching objectives such as recognition, inclusion and rights), then we have to ask ourselves: what is the political nature of these expressions; what is their political potential; what is politically possible at these times; or, what are we talking about today, when we talk about politics?

\section{Bibliography}

Castles, Stephen / Miller, Mark J. (2003): The Age of Migration. $3^{\text {rd }}$ ed., New York: The Guilford Press.

Garretón, Manuel Antonio (1997): “Las transformaciones de la acción colectiva en América Latina”. In: Agustín Martínez (Coord.): Cultura política. Partidos y transformaciones en América Latina. Caracas: CLACSO.

Giddens, Anthony (1995): La constitución de la sociedad. Bases para la teoría de la estructuración. $1^{\text {st }}$ ed. in Spanish (translated by José Luis Etcheverry), Buenos, Aires: Amorrortu.

Held, David (1996): Modelos de democracia. $2^{\text {nd }}$ ed. in Spanish (translated by Teresa Albero), Madrid: Alianza.

Jacobson, David (1997): Rights Across Borders. Immigration and the Decline of Citizenship. London: The Johns Hopkins University Press.

Luhmann, Niklas / De Giorggi, Raffaele (1993): Teoría de la sociedad. 1st. ed. in Spanish (translated by Miguel Romero Pérez and Carlos Villalobos), México: Universidad de Guadalajara, Universidad iberoamericana, ITESO.

Melucci, Alberto (1996): “Individualización y globalización. Perspectivas teóricas” (translated by Clara Zapata Tarrés). In: Estudios Sociológicos, Vol. XIV, No. 41, México.

Santiago, José (2015): "La estructura social a la luz de las nuevas sociologías del individuo". In: Revista Española de Investigación Social, No. 149, pp. 131-151, Madrid. 
Saraví, Gonzálo (2009): Transiciones vulnerables: Juventud, desigualdad y exclusión en México. Mexico: CIESAS.

Sassen, Saskia (2003): Contrageografías de la globalización. Madrid: Traficantes de sueños.

Sassen, Saskia (2015): Expulsiones. Brutalidad y complejidad en la economía global. $1^{\text {st }}$ ed. (translated by Strella Mastrangelo), Buenos Aires: Katz.

Yañez, Sonia (2004): "La flexibilidad laboral como nuevo eje de la producción y la reproducción”. In: Todaro, Rosalba / Yañez, Sonia (Eds.): El trabajo se transforma.

Relaciones de producción y relaciones de género. Santiago de Chile: Centro de Estudios de la Mujer.

Zolo, Danilo (1994): Democracia y complejidad. Un enfoque realista. $1^{\text {st }}$ ed. in Spanish (translated by Horacio Pons), Buenos Aires: Nueva Visión. 